\title{
PROFIL PENCEMARAN LOGAM BERAT PADA PERAIRAN DAERAH ALIRAN SUNGAI (DAS) GRINDULU PACITAN
}

\author{
Titik Wijayanti ${ }^{1)}$ \\ ${ }^{1)}$ Program Studi Pendidikan Biologi IKIP Budi Utomo Malang \\ Jl. Citandui 46 Malang (Kampus C) \\ Email: kititn71@gmail.com
}

\begin{abstract}
ABSTRAK
Telah dilakukan penelitian untuk mengetahui tingkat pencemaran logam berat pada perairan Daerah Aliran Sungai (DAS) Grindulu, Pacitan. Penelitian dilaksanakan pada bulan SeptemberOktober 2016. Pengukuran kadar logam berat Merkuri $(\mathrm{Hg})$, Timbal $(\mathrm{Pb})$, Kadmium $(\mathrm{Cd})$, dan Kromium (Cr) sampel air yang diambil daerah hulu, terdiri dari 2 (dua) stasiun, yaitu desa Tumpuk kecamatan Bandar dan desa Tegalombo kecamatan Tegalombo. Pada daerah tengah, terdiri dari 2 stasiun, yaitu di desa Pagutan kecamatan Arjosari dan desa Semanten kecamatan Arjosari. Pada daerah hilir diamati satu stasiun di desa Ploso kecamatan Pacitan. Data yang diperoleh dianalisis anova dan uji lanjut Duncan 5\%. Hasil penelitian menunjukkan adanya perbedaan signifikan pada semua stasiun pengambilan sampel terhadap semua logam berat dan terjadi kenaikan kadar mulai dari daerah tengah sampai hilir. Kadar logam berat merkuri $(\mathrm{Hg})$, timbal $(\mathrm{Pb})$ dan kadmium $(\mathrm{Cd})$ di daerah hulu masih di bawah ambang batas, sedangkan pada daerah tengah dan hilir sudah melebihi ambang batas yang ditentukan. Sedangkan pada logam berat kromium valensi $6\left(\mathrm{Cr}^{6+}\right)$, kadar di daerah hulu sampai tengah masih di bawah ambang batas, sedangkan daerah hilir sudah melebihi ambang batas yang ditentukan.
\end{abstract}

Kata kunci: Pencemaran, logam berat, air, Grindulu, Pacitan

\section{HEAVY METALS POLLUTANT PROFILE ON GRINDULU WATERSHED, PACITAN}

\begin{abstract}
Research was conducted to determine the level of heavy metal pollution in the water at the Watershed (DAS) Grindulu, Pacitan. The research was conducted in September-October 2016. Measurement of levels of heavy metals Mercury $(\mathrm{Hg})$, Lead $(\mathrm{Pb})$, Cadmium $(\mathrm{Cd})$ and chromium (Cr) water samples taken upstream area, consisting of two (2) stations, Tumpuk, and Tegalombo. In the middle area, consists of two stations, Pagutan and Semanten Arjosari. In the downstream area of the station at Ploso. The Data were analyzed ANOVA and Duncan's test 5\%. The results showed significant differences in all sampling stations on all heavy metals and an increase in levels ranging from middle to downstream areas. Levels of heavy metals mercury $(\mathrm{Hg})$, lead $(\mathrm{Pb})$ and cadmium $(\mathrm{Cd})$ upstream still below the threshold, whereas in the midstream and downstream areas has exceeded a specified threshold. While the heavy metal chromium $\left(\mathrm{Cr}^{6+}\right)$, levels in the upstream region until the middle is still below the threshold, whereas the downstream areas already exceeds the specified threshold.
\end{abstract}

Keywords: Pollution, heavy metal, water, Grindulu, Pacitan

\section{PENDAHULUAN}

Sungai sebagai salah satu komponen lingkungan yang mempunyai fungsi penting bagi kehidupan manusia termasuk untuk menunjang keseimbangan lingkungan. Sebagai akibat adanya peningkatan pembangunan diberbagai bidang maka baik secara langsung maupun tidak langsung akan mempunyai dampak terhadap kerusakan lingkungan termasuk didalamnya pencemaran sungai yang berasal dari limbah domestik maupun non domestik seperti pabrik dan industri. Oleh karena itu, pencemaran air sungai dan lingkungan sekitarnya perlu dikendalikan seiring dengan 
laju pembangunan agar fungsi sungai dapat dipertahankan kelestariannya.

Berdasarkan peta rupa bumi yang dikeluarkan oleh Badan Koordinasi Survey dan Pemetaan Nasional, sungai Grindulu adalah sungai di Pulau Jawa dengan letak geografis berada $110^{\circ} 55^{\prime}-111^{\circ} 25^{\prime} \mathrm{BT}$ dan $7^{\circ} 55^{\prime}-8^{\circ} 17^{\prime}$ LS. Menurut Permen PU no.39/PRT/1989 tentang pembagian wilayah sungai, sungai Grindulu termasuk dalam wilayah sungai Bengawan Solo. Informasi yang didapat dari dokumen Status Lingkungan Hidup kabupaten Pacitan tahun 2010 dan Dinas Bina Marga dan Pengairan Kab. Pacitan, 2011) dinyatakan bahwa DAS Grindulu berada di tiga wilayah yakni Kabupaten Pacitan, Kabupaten Ponorogo dan Kabupaten Wonogiri dengan luas kirakira $655,4 \mathrm{Km} 2$ dan $90,6 \%$ atau seluas 593,8 Km2 masuk wilayah Kabupaten Pacitan. DAS Grindulu yang mengalir mulai dari Gunung Gembes (1.200 mdpl) di perbatasan Desa Jeruk dengan Desa Bangunsari di Kecamatan Bandar lalu melewati Kecamatan Tegalombo, Kecamatan Arjosari, Kecamatan Pacitan dan bermuara di Samudera Hindia, tepatnya di Kelurahan Ploso. Sungai Grindulu memiliki panjang sekira 60 kilometer berarah timur laut-baratdayaselatan.

Masyarakat di sepanjang DAS (Daerah Aliran Sungai) memanfaatkan air sungai grindulu untuk berbagai aktivitas, seperti mandi, mencuci, dan keperluan irigasi pertanian lebih banyak pada daerah yang memiliki tekstur tanah yang datar, misalnya wilayah kecamatan Tegalombo dan kecamatan Pacitan. Sedangkan daerah dengan tekstur tanah yang berbukit, hanya diambil manfaat batu dan pasir untuk material pembangunan rumah ataupun gedung. Sungai grindulu juga digunakan untuk pemancingan oleh masyarakat setempat. Ikan yang sering ditemukan diantaranya ikan nila, lele, belut, carper, wader, nyerek, udang tawar dan lain sebagainya (Purnawan, 2012).

Pada saat ini terdapat dua pabrik disepanjang DAS grindulu. Dua pabrik tersebut adalah pabrik pertambangan timah milik PT Gemilang Limpah Internusa (GLI) yang ada di Desa Cokrokembang, Kecamatan Ngadirejo, Kabupaten Pacitan dan perusahaan pertambagan seng $(\mathrm{Zn})$ dan tembaga $(\mathrm{Cu})$ PT Dragon Fly Mineral
Industri (DFMI) yang berlokasi di jalan Raya Pagotan Kecamatan Arjosari Kabupaten Pacitan (Aji, 2010). Pembangunan pabrik disekitar DAS (Daerah Aliran Sungai) menimbulkan kekhawatiran yang besar. Salah satunya adalah pencemaran lingkungan perairan terutama akibat kontaminasi sisa limbah industri yang berupa logam berat. Logam berat yang seringkali turut terbuang bersama limbah industri dan akan menjadi agen pencemar di lingkungan antara lain: Timbal $(\mathrm{Pb})$, merkuri $(\mathrm{Hg})$, Kadmium (Cd), Arsen (As), Timah (Ni), Krom $(\mathrm{Cr})$, Tembaga $(\mathrm{Cu})$, Seng $(\mathrm{Zn})$ dan lain sebagainya (Taftazani, 2005; Rochyatun, dkk 2006; Priyanto, dkk, 2008 dan Supenah, dkk, 2015)

Seperti diketahui logam berat $\mathrm{Hg}$, $\mathrm{Cd}, \mathrm{Pb}, \mathrm{Cr}$ termasuk jenis logam berat tidak esensial, dimana keberadaannya dalam tubuh masih belum diketahui manfaatnya atau bahkan dapat bersifat racun, seperti dan sebagainya. Merkuri merupakan satu-satunya logam yang berada dalam bentuk cair pada suhu normal. Kadar Hg pada perairan tawar alami berkisar 10-100 nm/l (Moore, 1991). Merkuri terdapat di alam dalam bentuk logam, garam anorganik dan garam organik. Dalam bentuk garam anorganik merkuri dapat menyebabkan kerusakan hati dan ginjal, karena timbunan $\mathrm{Hg}$ yang paling tinggi terdapat pada organ hepar dan ginjal (Palar, 1994; Supriharyono, 2000 dan Effendi, 2000). Akumulasi $\mathrm{Hg}$ dalam tubuh dapat menyebabkan termor, parkinson, gangguan lensa mata berwarna abu-abu, gangguan syaraf dan pada akhirnya kematian (Linder, 2010). Timbal (Pb) merupakan logam berat yang mempunyai tingkat toksisitas yang tinggi. Akumulasi timbal terbanyak biasanya terdapat pada aorta, liver, ginjal, pankreas, paru-paru, tulang, limpa, testis, jantung dan otak (Sulistia, 1980 dalam Supriyanto, dkk., 2007; Linder, 2010). Keracunan $\mathrm{Pb}$ dapat menyebabkan ensefalopati, kerusakan arteriol dan kapiler, edeme otak dan kerusakan organ yang cukup parah (Linder, 2010). Logam berat kadmium (Cd) dan kromium (Cr) merupakan jenis logam yang banyak ditemukan diperairan (Borkar et al., 2006). Dampak negatif kadmium dalam tubuh adalah terjadinya kerusakan ginjal. Selain itu, juga dapat menyebabkan gangguan pertumbuhan, reproduksi, menyebabkan hipertensi, 
teratogenesis dan bahkan kanker (Linder, 2010). Logam $\mathrm{Cr}^{6+}$ merupakan bentuk kromium yang memiliki dampak negatif bagi kesehatan (Bielicka, et al., 2005). Keracunan $\mathrm{Cr}^{6+}$ dapat menyebabkan ganguan kulit, pencernaan, pernafasan, kerusakan organ, perubahan materi genetis dan kematian (Linder, 2010).

Berdasarkan uraian di atas, penulis melakukan kegiatan penelitian yang bertujuan mengetahui kandungan logam berat pada DAS Grindulu mulai dari daerah hulu, tengah dan hilir sehingga dapat memberikan informasi yang tepat pada pengambilan langkah konservasi yang tepat bertajuk Profil Pencemaran Logam Berat pada Perairan Daerah Aliran Sungai (DAS) Grindulu Pacitan.

\section{METODE PENELITIAN}

Penelitian ini akan dilakukan pada bulan September sampai dengan Oktober 2016. Pengambilan sampel dilakukan secara in situ di sungai Grindulu Pacitan, pada 5 (lima) stasiun, yaitu stasiun 1 desa Tumpuk kecamatan Bandar, stasiun 2 desa Tegalombo kecamatan Tegalombo, stasiun 3 desa Pagutan kecamatan Arjosari, stasiun 4 desa Semanten kecamatan Arjosari, stasiun 5 desa Ploso kecamatan Pacitan. Penentuan koodinat lokasi menggunakan metode GPS Google Maps dan Google Earth (Google, 2016). Tiap stasiun dilakukan pengulangan sebanyak 3 kali.

Pengukuran kadar logam berat Merkuri (Hg), Timbal (Pb), Kadmium (Cd), dan Kromium $\left(\mathrm{Cr}^{6+}\right)$ dilakukan di laboratorium Biologi IKIP Budi Utomo Malang dan di Laboratorium Ekologi dan
Diversitas Hewan Universitas Brawijaya Malang.

Penentuan kuantitatif logam berat $\mathrm{Hg}, \mathrm{Pb}, \mathrm{Cd}$, dan $\mathrm{Cr}^{6+}$ menggunakan metode spektrofotometri serapan atom (Balai Penelitian Tanah Deptan RI, 2005). Data yang diperoleh dilakukan uji anova dan uji lanjut Duncan 5\% dengan menggunakan program komputasi statistik SPSS v. 21 (IBM, 2012).

\section{HASIL DAN PEMBAHASAN}

Pengamatan kadar logam berat $\mathrm{Hg}$, $\mathrm{Pb}, \mathrm{Cd}$, dan $\mathrm{Cr}^{6+}$ dilakukan pada 5 stasiun yang mewakili daerah hulu, tengah dan hilir pada DAS Grindulu. Pada daerah hulu, terdiri dari 2 (dua) stasiun, yaitu desa Tumpuk kecamatan Bandar dan desa Tegalombo kecamatan Tegalombo. Pada daerah tengah, terdiri dari 2 stasiun, yaitu di desa Pagutan kecamatan Arjosari dan desa Semanten kecamatan Arjosari. Pada daerah hilir diamati satu stasiun di desa Ploso kecamatan Pacitan.

Secara geografis, stasiun 1 yang terletak di desa Tumpuk kecamatan Bandar

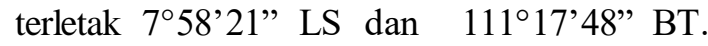
Stasiun 2 yang terletak di desa Tegalombo kecamatan Tegalombo terletak 8०3'58' LS dan $111^{\circ} 17^{\prime} 51^{\prime \prime}$ BT. Stasiun 3 yang terletak di desa Pagutan kecamatan Arjosari secara geografis terletak pada $8^{\circ} 7^{\prime} 40^{\prime \prime}$ LS dan $111^{\circ} 8$ '56" BT. Stasiun 4 yang terletak di desa Sematen kecamatan Arjosari secara geografis terletak pada $8^{\circ} 10^{\prime} 28^{\prime \prime}$ LS dan $111^{\circ} 7^{\prime} 21^{\prime \prime}$ BT. Stasiun 5 yang terletak di desa Ploso kecamatan Pacitan secara geografis terletak pada $8^{\circ} 12^{\prime} 50^{\prime \prime}$ LS dan $111^{\circ} 6$ ' 42”' BT.

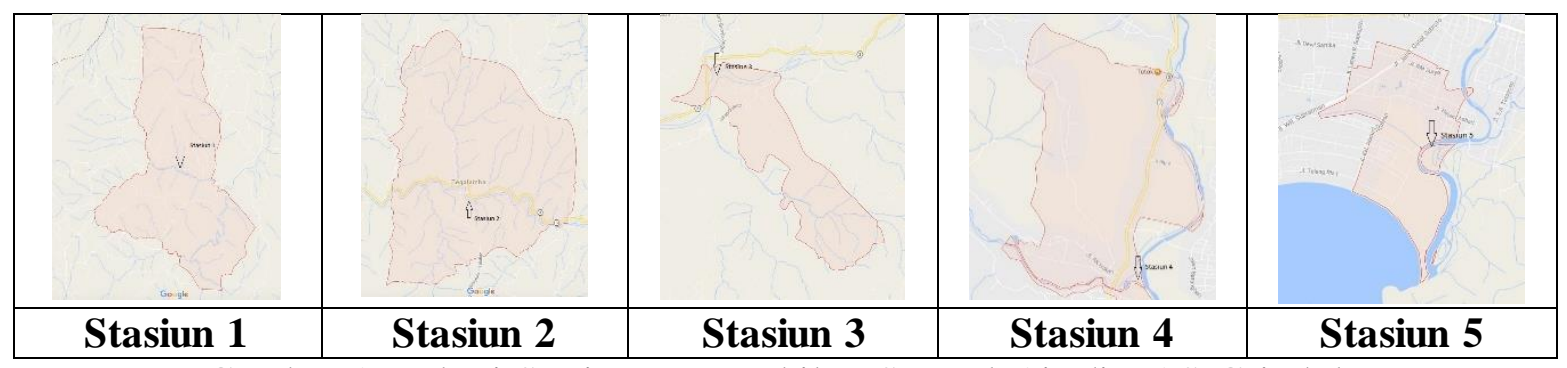

Gambar 1. Lokasi Stasiun Pengambilan Sampel Air di DAS Grindulu

Gambaran kadar logam berat $\mathrm{Hg}$, $\mathrm{Pb}, \mathrm{Cd}$ dan $\mathrm{Cr}^{6+}$ pada semua stasiun mulai dari hulu (stasiun 1 dan 2), tengah (stasiun 3 dan 4) dan hilir (stasiun 5) DAS Grindulu dapat dilihat pada gambar 2 . 


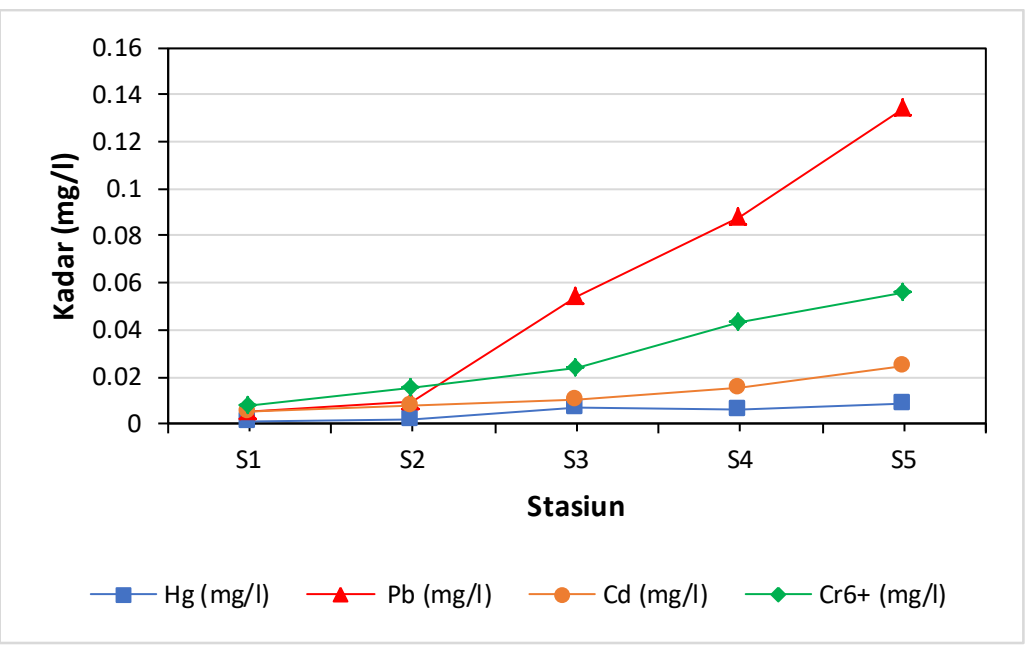

Gambar 2. Gambaran kadar logam berat di DAS Grindulu Pacitan

Gambar 2 menunjukkan bahwa pada semua jenis logam berat yang diteliti, terdapat kenaikan kadar seiring dengan pergeseran stasiun pengamatan dari hulu ke arah hilir. Hal ini menunjukkan bahwa terdapat penambahan kadar logam berat yang terlarut pada air sungai karena berbagai faktor. Kenaikan yang cukup signifikan terjadi mulai pada stasiun 3 yang terletak di desa Pagutan kecamatan Arjosari sampai ke hilir pada stasiun 5 di desa Ploso kecamatan
Pacitan. Kadar logam berat tertinggi terjadi pada logam berat merkuri $(\mathrm{Pb})$ dan yang paling rendah adalah merkuri $(\mathrm{Hg})$.

Hasil uji anova menunjukkan bahwa adanya perbedaan yang signifikan pada stasiun pengambilan sampel terhadap semua logam berat, baik merkuri $(\mathrm{Hg})$, timbal $(\mathrm{Pb})$, kadmium (Cd) dan kromium valensi 6 $\left(\mathrm{Cr}^{6+}\right)$. Hasil uji Duncan 5\% terhadap rerata kadar logam yang diteliti dapat dilihat pada tabel.

Tabel. Hasil Uji Duncan 5\% Rerata Kadar Logam Berat pada Stasiun Pengamatan DAS Grindulu

\begin{tabular}{|l|c|c|c|c|}
\hline \multirow{2}{*}{ Stasiun/daerah } & \multicolumn{4}{|c|}{ Kadar logam berat (mg/l) } \\
\cline { 2 - 5 } & Hg & Pb & Cd & $\mathbf{C r}^{\text {6+ }}$ \\
\hline S1 (hulu) & $0,0014 \mathrm{a}$ & $0,0056 \mathrm{a}$ & $0,0049 \mathrm{a}$ & $0,0077 \mathrm{a}$ \\
\hline S2 (hulu) & $0,0019 \mathrm{a}$ & $0,0098 \mathrm{a}$ & $0,0080 \mathrm{~b}$ & $0,0156 \mathrm{~b}$ \\
\hline S3 (tengah & $0,0068 \mathrm{~b}$ & $0,0538 \mathrm{~b}$ & $0,0104 \mathrm{c}$ & $0,0241 \mathrm{c}$ \\
\hline S4 (tengah) & $0,0060 \mathrm{~b}$ & $0,0876 \mathrm{c}$ & $0,0155 \mathrm{~d}$ & $0,0434 \mathrm{~d}$ \\
\hline S5 (hilir) & $0,0089 \mathrm{c}$ & $0,1341 \mathrm{~d}$ & $0,0247 \mathrm{e}$ & $0,0562 \mathrm{e}$ \\
\hline
\end{tabular}

Keterangan: Angka yang diikuti huruf yang sama tidak berbeda nyata pada uji Duncan 5\%

Tabel 1 menunjukkan bahwa pada parameter logam berat merkuri $(\mathrm{Hg})$, pada stasiun 1 dan 2 yang terletak di hulu tidak terjadi perbedaan yang nyata. Pada daerah tengah, yaitu stasiun stasiun 3 dan 4 , terjadi kenaikan kadar merkuri $(\mathrm{Hg})$ dan berbeda nyata dengan stasiun pengamatan di daerah hulu. Namun begitu tidak terdapat perbedaan yang signifikan antara stasiun 3 dan stasiun 4 pada parameter kadar merkuri $(\mathrm{Hg})$. Kadar merkuri (Hg) pada daerah hilir, yaitu pada stasiun 5 memiliki kadar merkuri $(\mathrm{Hg})$ tertinggi dan berbeda nyata dengan daerah hulu dan tengah DAS.

Tabel 1 juga menunjukkan bahwa kadar timbal $(\mathrm{Pb})$, pada stasiun 1 dan 2 yang terletak di hulu tidak terjadi perbedaan yang nyata. Sedangkan mulai stasiun 3 sampai dengan 5 terjadi peningkatan dan terdapat perbedaan yang sinifikan. Kadar timbal $(\mathrm{Pb})$ tertinggi, terjadi pada stasiun 5 yang terdapat di daerah hilir DAS Grindulu.

Tabel 1 juga menunjukkan bahwa pada parameter logam berat kadmium $(\mathrm{Cd})$ 
dan kromium valensi $6\left(\mathrm{Cr}^{6+}\right)$, terjadi perbedaan yang nyata pada semua stasiun pengamatan. Kadar kadmium (Cd) dan kromium valensi $6\left(\mathrm{Cr}^{6+}\right)$ tertinggi terjadi pada stasiun 5 yang terdapat di daerah hilir DAS Grindulu.

Seperti diketahui, pada PP No. 82 tahun 2001 tentang Pengelolaan Kualitas Air dan Pengendalian Pencemaran Air, kadar ambang batas logam berat untuk baku air kelas 3, diatur sebagai berikut: merkuri $(\mathrm{Hg})$ sebesar $0,005 \mathrm{mg} / \mathrm{l}$, timbal $(\mathrm{Pb})$ sebesar 0,03 $\mathrm{mg} / \mathrm{l}$, kadmium (Cd) sebesar $0,01 \mathrm{mg} / \mathrm{l}$, kromium valensi $6\left(\mathrm{Cr}^{6+}\right)$ sebesar $0,05 \mathrm{mg} / \mathrm{l}$.

Jika kadar logam berat yang diteliti di DAS Grindulu tersebut dibandingkan dengan PP No. 82 tahun 2001, maka pada logam berat merkuri $(\mathrm{Hg})$, timbal $(\mathrm{Pb})$ dan kadmium (Cd), kadar logam ketiga jenis logam berat tersebut di daerah hulu masih di bawah ambang batas, sedangkan pada daerah tengah dan hilir sudah melebihi ambang batas yang ditentukan. Sedangkan pada logam berat kromium valensi $6\left(\mathrm{Cr}^{6+}\right)$, kadar di daerah hulu sampai tengah masih di bawah ambang batas, sedangkan daerah hilir sudah melebihi ambang batas yang ditentukan.

Faktor-faktor yang menyebabkan peningkatan kadar logam berat pada daerah tengah dan hilir disebabkan oleh tiga faktor, faktor pertama, adalah adanya pengikisan mineral batuan DAS grindulu pada daerah hulu. Hal ini dikarenakan daerah hulu sebuah DAS mempunyai ciri-ciri terjadi proses pendalaman lembah sepanjang aliran sungai, laju erosi lebih cepat daripada pengendapan, kerapatan drainase yang lebih tinggi, lereng terjal. Pengikisan mineral dari daerah hulu akan mengendap pada daerah tengah dan hilir DAS (Harjadi, 2009; Fatmasari, 2010; Saputri, 2010). Faktor kedua, adalah tipologi daerah tengah dan hilir yang dicirikan dengan mulai terjadinya proses pengendapan dan sedikit erosi. Sehingga terjadi akumulasi kadar logam berat pada air dan sedimen sungai (Fatmasari, 2010) Faktor ketiga, adanya penambahan zat pencemar air yang berasal dari aktifitas manusia. Seperti diketahui, aktifitas manusia yang membuang sisa aktifitas dan aktifitas yang berhubungan dengan sungai semakin ke arah hilir akan semakin banyak. Sehingga potensi kenaikan zat pencemar yang ada di DAS akan semakin meningkat pula (Susanti, 2014 dan Supenah, dkk, 2015). Diduga, kontribusi terbesar pencemar, pada DAS Grindulu adalah aktifitas perusahaan tambang logam dan adanya aktifitas pengambilan material sungai yang mulai menggunakan alat berat, sehingga dimungkinkan terjadi kebocoran bahan bakar atau cairan kimia, seperti oli ke DAS Grindulu (Taftazani, 2005; Aji, 2010; Rahman, 2011; Purnawan, 2012).

Hasil penelitian yang dilakukan oleh Rahman (2011) juga menunjukkan bahwa kualitas air sungai DAS Grindulu pada daerah tengah dan hilir melebihi ambang batas untuk digunakan sebagai air minum (Permenkes no 416 tahun 1990), sehingga perlu pengolahan terlebih dahulu jika hendak digunakan sebagai air minum.

Sehingga dengan demikian, perlu disiapkan langkah-langkah strategis jangka pendek dan jangka menengah sebagai upaya konservasi dalam menurunkan kadar logam berat di daerah tengah dan hilir DAS Grindulu. Upaya-upaya yang bisa dilakukan adalah menjalankan pengawasan AMDAL pada perusahaan-perusahaan yang beroperasi di sekitar DAS Grindulu, mendirikan pospos pemantauan kualitas air di DAS Grindulu, menggerakkan masyarakat disekitar DAS untuk turut serta dalam menjaga sungai, melakukan reboisasi pada daerah hulu, sehingga menurunkan resiko longsor. Langkah menengah adalah melakukan penataan tata ruang yang berbasis konservasi yang dapat dilakukan jangka panjang.

\section{KESIMPULAN}

Berdasarkan penelitian yang telah dilakukan, dapat disimpulkan bahwa kadar logam berat merkuri $(\mathrm{Hg})$, timbal $(\mathrm{Pb})$ dan kadmium (Cd) di daerah hulu masih di bawah ambang batas, sedangkan pada daerah tengah dan hilir sudah melebihi ambang batas yang ditentukan. Sedangkan kadar kromium valensi $6\left(\mathrm{Cr}^{6+}\right)$, di daerah hulu sampai tengah masih di bawah ambang batas, sedangkan daerah hilir sudah melebihi ambang batas yang ditentukan. Sehingga perlu dilakukan langkah-langkah konservasi DAS untuk mereduksi kandungan logam berat agar tidak terjadi kenaikan. 


\section{DAFTAR PUSTAKA}

Aji, H. 2010. Pacitan, Lingkungan Hidup Rusak Karena Tambang. Posted by handayaaji blog, pada 27 Agustus, 2010.

Bielicka, A., I. Bojanowska, and A. Wisniewski. 2005. Two faces of chromium-pollutant and bioelement, Polish Journal of Environmental Studies, Vol.14(1): 5-10.

Balai Penelitian Tanah Deptan RI. 2005. Petunjuk Teknis Analisis Kimia Tanah, Tanaman, Air dan Pupuk. Balai Penelitian Tanah, Badan Penelitian dan Pengembangan Pertanian Departemen Pertanian RI.

Borkar, M.U., R.P. Athalye and G. Quadros. 2006. Occurrence of heavy metals in abiotic and biotic components of the mangrove ecosystem of Thane Creek. $J$ Ecol. Env.\& Cons., Vol. 12 (4): $723-$ 728.

Dokumen SLHD. 2010. Dokumen SLHD Kabupaten Pacitan Tahun 2010. Pacitan.

Dinas Bina Marga dan Pengairan Kab. Pacitan. 2011. Gambaran Umum Kabupaten Pacitan. Pemerintah Kabupaten Pacitan-Jawa Timur.

Effendi, H. 2000. Telaah Kualitas Air. Institut Pertanian Bogor: Bogor.

Fatmasari, I. 2009. Tingkat Risiko Longsor dan Arahan Konservasi Lahan DAS Grindulu Hulu Kabupaten Pacitan dan Ponorogo. Skripsi. Fakultas Keguruan dan Ilmu Pendidikan Universitas Sebelas Maret Surakarta.

Google Inc. 2016. Google Maps/Google Earth version 4.27.58. Google Inc

Harjadi, B. 2009. Monitoring dan evaluasi daerah aliran sungai dengan penginderaan jauh dan sistem informasi geografis. J. Forum Geografi, Vol. 23 (2): 139-152.

IBM Inc. 2012. IBM SPSS Statistic v 2132 bit edition. IBM Corporation.
Linder, M.C. 2010. Biokimia Nutrisi Dan Metabolisme: Dengan Pemakaian Secara Klinis. Department of Chemistry, California State University, Fullerton. Diterjemahkan oleh: Aminuddin Parakkasi. UI-Press. Jakarta.

Moore, H.P. 1991. Pencemaran Laut oleh Logam Berat: dalam Status Pencemaran Laut di Indonesia dan Teknik Pemantauannya. P3O-LIPI. Jakarta.

Pemerintah RI. 1989. Peraturan Menteri Pekerjaan Umum No. 39/PRT/1989 Tentang Pembagian Wilayah Sungai. Kementerian Pekerjaan Umum RI.

Palar, H. 1994. Pencemaran dan Toksikologi Logam Berat. Rineka Cipta: Jakarta.

Peraturan Pemerintah (PP) RI No. 82 Tahun 2001 Tentang Pengelolaan Kualitas Air dan Pengendalian Pencemaran Air.

Priyanto, N. Dwiyitno, dan A. Farida. 2008. Kandungan logam berat $(\mathrm{Hg}, \mathrm{Pb}, \mathrm{Cd}$ dan $\mathrm{Cu}$ ) pada ikan, air, dan sedimen di waduk cirata, jawa barat. Jurnal Pascapanen dan Bioteknologi Kelautan dan Perikanan, Vol. 3(1): 69-78

Putri, Y.K. 2010. Daerah Aliran Sungai Grindulu (Pacitan, Jawa Timur). Tugas pengelolaan DAS. Fakultas Pengairan, Universitas Indonesia. Jakarta.

Purnawan, D. 2012. Sungai Grindulu, Sebuah Identitas dan Kekayaan Alam Pacitan. Tinta Harmoni Blog, posted 22 Oktober 2012.

Rochyatun, E., K. Taufik, dan R. Abdul. 2006. Distribusi logam berat dalam air dan sedimen di perairan muara sungai cisedane. J Makara Sains, Vol. 10 (1): $35-40$

Rahman, K MS. 2011. Implementasi Peraturan Pemerintah No. 82 Tahun 2001 dan Peraturan Menteri Kesehatan No. 416 Tahun 1990 Di Instalasi Pengelolaan Air PDAM Kabupaten Pacitan Tahun 2011. Tesis. Program Pascasarjana Universitas Sebelas Maret Surakarta. 
Supriharyono. 2000. Pelestarian dan Pemanfaatan Sumberdaya Alam di Wilayah Pesisir Tropis. Gramedia Pustaka Utama: Jakarta.

Supriyanto, C., Samin, Z. Karim. 2007. Analisis Cemaran Logam Berat $\mathrm{Pb}$, $\mathrm{Cu}$, Dan $\mathrm{Cd}$ Pada Ikan Air Tawar Dengan Metode Spektrometri Nyala Serapan Atom (SSA). Seminar Nasional III ISSN. 1978-0176, SDM Teknologi Nuklir, Pusat Teknologi Akselerator dan Proses Bahan. D.I Yogyakarta.

Saputri. 2010. Analisis Kemampuan Lahan Dengan Menggunakan Penginderaan Jauh dan Sistem Informasi Geografi di DAS Grindulu Pacitan Propinsi Jawa Timur. Skripsi. Fakultas Pertanian Universitas Sebelas Maret Surakarta.
Susanti, R, Dewi, M, Fitri AS, 2014. Analisis kadar logam berat pada sungai di jawa tengah. Jurnal Sains dan Teknologi Sainteknol, Vol. 12(1): 35-40

Supenah, P., Endang W, dan Rawuh EP, 2015. Kajian kualitas air sungai condong yang terkena buangan limbah cair industri batik trusmi cirebon. $J$ Biosfera Vol. 32(2): 113-118

Taftazani, A., Muzakky, dan Sumining. 2005. Evaluasi Kadar Logam Berat Dalam Sampel Lingkungan Pantai Indramayu Dengan Teknik Analisis Aktivasi Neutron. Prosiding PPI PDIPTN 2005, ISSN: 0216 - 3128. Puslitbang Teknologi Maju - Batan. Jogjakarta. 